\title{
Phenotypic screening using large-scale genomic libraries to identify drug targets for the treatment of cancer (Review)
}

\author{
MITSUO SATO \\ Department of Pathophysiological Laboratory Sciences, Nagoya University \\ Graduate School of Medicine, Nagoya, Aichi 461-8673, Japan
}

Received October 21, 2019; Accepted February 4, 2020

DOI: $10.3892 / \mathrm{ol} .2020 .11512$

\begin{abstract}
During malignant progression to overt cancer cells, normal cells accumulate multiple genetic and non-genetic changes, which result in the acquisition of various oncogenic properties, such as uncontrolled proliferation, drug resistance, invasiveness, anoikis-resistance, the ability to bypass oncogene-induced senescence and cancer stemness. To identify potential novel drug targets contributing to these malignant phenotypes, researchers have performed large-scale genomic screening using various in vitro and in vivo screening models and identified numerous promising cancer drug target genes. However, there are issues with these identified genes, such as low reproducibility between different datasets. In the present study, the recent advances in the functional screening for identification of cancer drug target genes are summarized, and current issues and future perspectives are discussed.
\end{abstract}

\section{Contents}

1. Introduction

2. Types of functional screening according to phenotypes used

3. Conclusions and future perspectives

\section{Introduction}

Most human solid tumors develop through multi-step carcinogenesis $(1,2)$. During this process, normal cells, presumed to be tissue-specific stem cells, accumulate multiple

Correspondence to: Dr Mitsuo Sato, Department of Pathophysiological Laboratory Sciences, Nagoya University Graduate School of Medicine, 1-1-20 Daiko-Minami, Higashi-ku, Nagoya, Aichi 461-8673, Japan

E-mail: msato@met.nagoya-u.ac.jp

Key words: RNA interference, short hairpin RNA, CRISPR-Cas9, single-guide RNA, synthetic lethal, anoikis, oncogene induced senescence, cancer stemness molecular changes advantageous to step-wise growth, finally transforming into overt cancer cells (3). Previous advances in genome-wide profiling technologies have revealed a number of molecular changes in malignant cells at the genetic, epigenetic, transcriptional and translational levels (4-6). Genetic alterations in proto-oncogenes that significantly contribute to malignant phenotypes are called driver oncogenes, such as activated forms of epidermal growth factor receptor (EGFR), HER2/Neu and BRAF (7-10). There are multiple drugs that successfully target these driver oncogenes. For example, EGFR-targeted drugs, such as gefitinib and erlotinib, exhibit anti-cancer activity against lung cancer with activating mutations in $\operatorname{EGFR}(11,12)$.

However, it is difficult to pharmacologically inhibit oncogenic signaling of some driver oncogenes. For example, the development of mutant KRAS-targeted drugs has proven problematic over the previous three decades (13). Although recently, treatment with AMG510, a novel inhibitor against $K R A S G 12 C$, resulted in a promising response rate in patients with lung cancer harboring this specific type of mutation, development of drugs targeting other types of KRAS mutations have not yet been successful (14-16). In addition, mutations in driver oncogenes in a number of types of human cancer have not been identified (17). In such cases, cancer results from non-oncogenes conferring various malignant phenotypes, occasionally in a context-dependent manner (18) and these genes may serve as novel therapeutic targets. For example, a study demonstrated that cancer cells depend on non-oncogene Heat shock factor 1 (HSF1), which is the master regulator of the heat shock response in eukaryotes, for their proliferation and survival than their non-transformed counterparts (19). To identify drug target genes for cancer cells harboring oncogenes which are difficult to pharmacologically inhibit, or do not have known oncogenes, it is vital to perform an unbiased, large-scale functional screening (20). Two important gene modulating technologies, RNA interference (RNAi) and clustered regularly interspaced short palindromic repeats-associated protein 9 (CRISPR-Cas9) have emerged as powerful tools for evaluating gene function (21). In addition, technologies in next generation sequencing have improved. The combination of these advanced technologies has allowed investigation of gene function at genome-wide levels in a high-throughput manner.

Thus, functional screening based on cancer-specific characteristics has been extensively conducted. In the 
majority of cases, functional screening is a four-step process: i) Inducing loss-of-function via RNA interference (RNAi) or CRISPR-Cas9 in cells; ii) evaluating the effects of the loss of the selected gene on phenotypes critical to cancer cells; iii) quantifying short hairpin RNAs (shRNAs) or single-guide RNAs (sgRNAs) via next-generation sequencing or microarray hybridization; and iv) data analysis (Fig. 1). Malignant phenotypes used for functional screening include uncontrolled promoted proliferation, drug resistance, invasiveness and the ability to bypass oncogene-induced senescence (OIS). In the present study, the recent advances in functional screening to identify cancer drug target genes have been summarized, and current issues and future perspectives have been discussed.

\section{Types of functional screening according to phenotypes used}

Dropout viability screening. Using genome-wide methodologies to identify target genes that substantially contribute to the uncontrolled proliferation of cancer cells is a straightforward approach to discovering cancer drug target genes for new drug development. This type of assay is called dropout viability screening. Two pioneering studies have conducted genome-wide dropout shRNA screening in various human cancer cell lines and identified genes essential for cancer cells $(22,23)$. The Project Achilles study (launched in 2011) systemically identified genes essential for proliferation and/or survival in particular cancer cell types (genetic vulnerabilities) by performing an integrative analysis involving two steps: i) Conducting a pooled shRNA screen that targeted 11,194 genes in 102 (updated to 216 in the latest study) human cancer cell lines, including ovarian, colon, pancreatic, esophageal and non-small cell lung cancers; and ii) combining these results with information on alterations of cancer genome through using publicly available databases $(24,25)$. By analyzing such diverse types of cancer, the study identified a number of lineage-specific essential genes. Another similar study used a pooled shRNA library comprised of 72 breast, pancreatic and ovarian cancer cell lines (26). In addition, after a CRISPR-Cas9-mediated gene-knockout technology became available in the experimental cell biology field (27), two studies demonstrated the feasibility of using lentiviral CRISPR-Cas9 libraries for functional screening, with certain advantages over RNAi libraries in efficacy and reliability $(28,29)$. Via negative screening with RNAi or CRISPR-Cas9, these studies identified genes essential for proliferation in cancer cells, of which certain genes were lineage-specific.

One critical issue resulting from the nature of dropout viability screening is that such identified essential genes for cancer cells may also be essential for normal cells; for example, housekeeping genes involved in the ribosomal, proteasomal and spliceosomal pathways (26). Nevertheless, such essential genes may serve as promising therapeutic targets, as cancer cells highly depend on them for proliferation and/or survival compared with normal cells. One way to identify general essential genes that are likely to serve as cancer drug targets is to integrate results of genomic library screening with gene expression data and copy number changes between cancer and normal cells (20). This helps identify the genes that are associated with proliferation and/or survival in cancer cells (24). Using this approach, two housekeeping genes have been identified, proteasome 20S subunit alpha 6 (PSMA6; a proteasomal catalytic subunit) and eukaryotic translation initiation factor 2 subunit beta (eIF2 $\beta$; a subunit of translation-initiation factor EIF2), as promising therapeutic targets for lung cancer $(30,31)$.

Another way to identify essential genes that contribute to oncogenic phenotypes is to reveal the genes which cancer cells depend on in specific contexts; for example, with certain types of driver oncogenes (32). This situation is referred to as synthetic lethality and is described later. One study demonstrated that an essential gene $B U D 31$, a component of the spliceosome is a potential therapeutic target specifically in MYC-driven cancers (33).

Synthetic lethality. A synthetic lethality refers to a phenomenon in which inhibition of one of two genes has no significant effects on cell viability but perturbation of both genes results in cell death (32). Synthetic lethality has attracted interest for the following reasons: i) If the synthetic lethality specifically occurs in cancer cells, treatments targeting genes involved in the synthetic lethality have a high therapeutic index; and ii) if the synthetic lethality involves driver oncogenes highly refractory to currently available treatment strategies, synthetic lethal genes may serve as good targets in types of cancer influenced by these oncogenes. A good example of such a gene is oncogenic $K R A S$, the most frequently mutated oncogene, although $K R A S$-targeted therapy is not used clinically (14). Using RNAi library screening, several studies have identified synthetic lethal genes in $K R A S$-mutated cancers, such as STK33, TBK1, PLK1, SNAIL2, CDK1 and GATA2 (34-39). However, these identified genes rarely overlapped between studies (40) and the identification of a synthetic lethal effect caused by $S T K 33$ has not been reproduced $(41,42)$. A recently conducted large-scale synthetic lethal RNAi screen, Project DRIVE, also failed to confirm significant synthetic interactions of mutant KRAS with these identified synthetic lethal genes (20). There are several possible reasons for such inconsistent results, including differences in methods of gene silencing (for example RNAi methodologies such as transient transfection of siRNAs or shRNA, and difference in types of library), and differences in types of cells used (for example variable dependencies on KRAS signaling). In particular, the latter seems to significantly influence screening results. Most studies of KRAS synthetic screens used cancer cell lines with or without mutant KRAS and/or isogenic cancer cell lines transfected with or without mutant KRAS (34-39). Cancer cell lines are highly variable in genetic changes (even those with the same driver oncogenes), which may result in inconsistent screening results $(17,43)$.

Project DRIVE comprehensively assessed dependencies and synthetic lethal relationships using 398 cancer cell lines from different organs (20). To minimize false-positive rates, an average of 20 shRNAs per gene were used and, although synthetic lethal genes could not be confirmed for mutant $K R A S$, a number of novel findings regarding synthetic lethality which are translatable to developing novel therapeutics were identified. For example, reduced expression levels of an anti-apoptotic protein BCL2L1, and increased expression levels of pro-apoptotic protein BIM, were the 
A Step 1: Loss of function

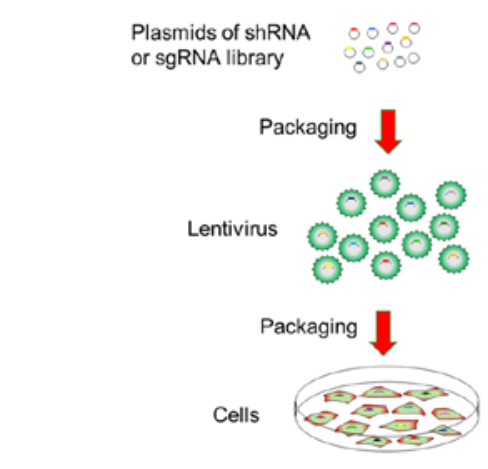

C Step 3: Quantifying shRNA
or sgRNA

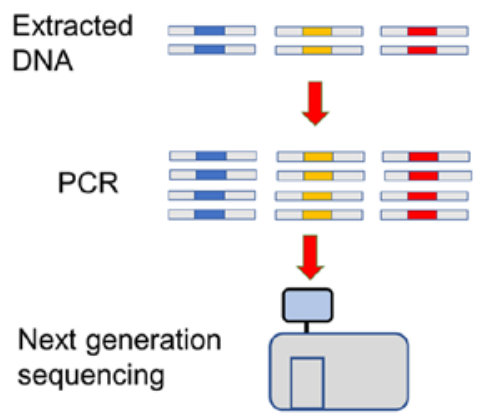

B Step 2: Phenotypic screen

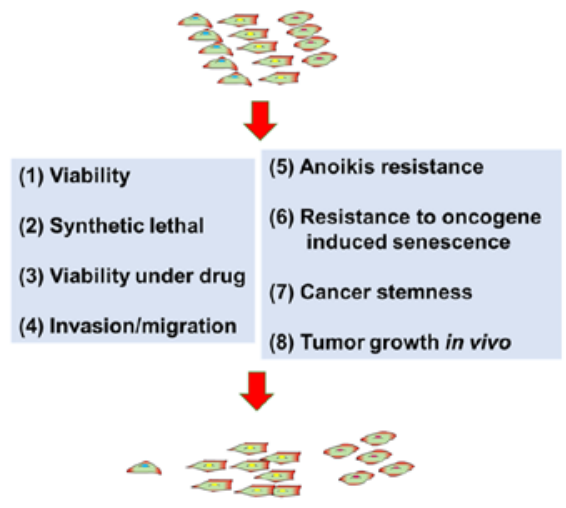

D Step 4: Data analysis

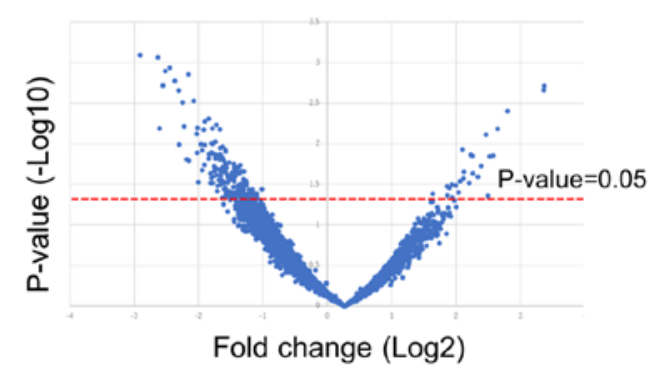

Figure 1. Flow diagram of the steps of phenotypic library screening with a genomic library for identifying cancer drug target genes. (A) Step 1: Loss of function, which is obtained by RNAi-mediated gene knockdown or Cas9-mediated gene knockout in cells. (B) Step 2: Phenotypic screen. Cells are subjected to various assays with different selection pressures including: 1, viability; 2, synthetic lethal; 3, viability under drug; 4, invasion/migration; 5, anoikis-resistance; 6, resistance to oncogene-induced senescence; 7, cancer stemness; and 8, tumor growth in vivo. (C) Step 3: Quantifying shRNA or sgRNA. DNA is extracted from harvested cells. Abundance of each shRNA or sgRNA is quantified using next-generation sequencing. (D) Step 4: Data analysis. Data are analyzed to generate ranked lists of promising cancer drug target genes. shRNA, short hairpin RNA; sgRNA, single-guide RNA.

strongest predictors of the growth-inhibiting effects following knockdown of anti-apoptotic protein myeloid cell leukemia sequence 1 (MCLI).

Recently, via genome-wide CRISPR-Cas9 screening, two independent groups identified WRN helicase as a synthetic lethal target in microsatellite unstable cancer types $(44,45)$. Moreover, a small molecule inhibitor of WRN helicase (NSC617145) has been revealed to exhibit cytotoxic effects in cells derived from patients with Fanconi anemia, in a synthetic lethal manner (46).

Dropout viability screening under drug treatment. Drug resistance is a critical problem in chemotherapy (47). Cancer can be resistant to a number of types of drugs, such as cytotoxic, molecular-targeted drugs and immune checkpoint inhibitors (47-49). Therefore, researchers focus extensively on finding therapeutic approaches to overcoming the development of drug resistance.

Dropout viability screening in the presence of anti-cancer drugs is a powerful approach to identifying genes responsible for drug resistance and several potentially chemo-sensitizing targets have been reported (Table I). Using a genome-wide an arrayed RNAi library, Whitehurst et al (50) identified several genes influencing resistance to paclitaxel in a lung cancer cell line. Lin et al (51) identified MCL1 as a potential drug target gene that sensitizes a small cell lung cancer cell line to ABT-737, an inhibitor of the antiapoptotic molecules Bcl-2, $\mathrm{Bcl}-\mathrm{X}(\mathrm{L})$ and Bcl-w. After the development of pooled RNAi library technology, numerous investigators began using such libraries. For example, Prahallad et al (52) revealed genes responsible for resistance to a $B R A F$ inhibitor PLX4032 (vemurafenib) in types of cancer harboring $B R A F \mathrm{~V} 600 \mathrm{E}$ mutations. It was revealed that EGFR activation, which is rapidly induced by vemurafenib treatment, induces resistance to vemurafenib treatment, suggesting that combination therapy of vemurafenib and an EGFR inhibitor may be beneficial. Previously, studies using CRISPR-Cas9 libraries were published. Most of these studies used the same type of genome-wide library, GeCKO CRISPR Library version 1 or 2, comprising of $>120,000$ sgRNAs targeting nearly the entire genome (53-56). For example, Sustic et al identified the endoplasmic reticulum to nucleus signaling 1 (ERN1)-JNK-JUN pathway as a potential target for improving the anti-cancer effects of MET inhibitors in KRAS-mutated colon cancer (56). $K R A S$-targeted therapy has not been successfully developed previously and, therefore, these findings are promising. 


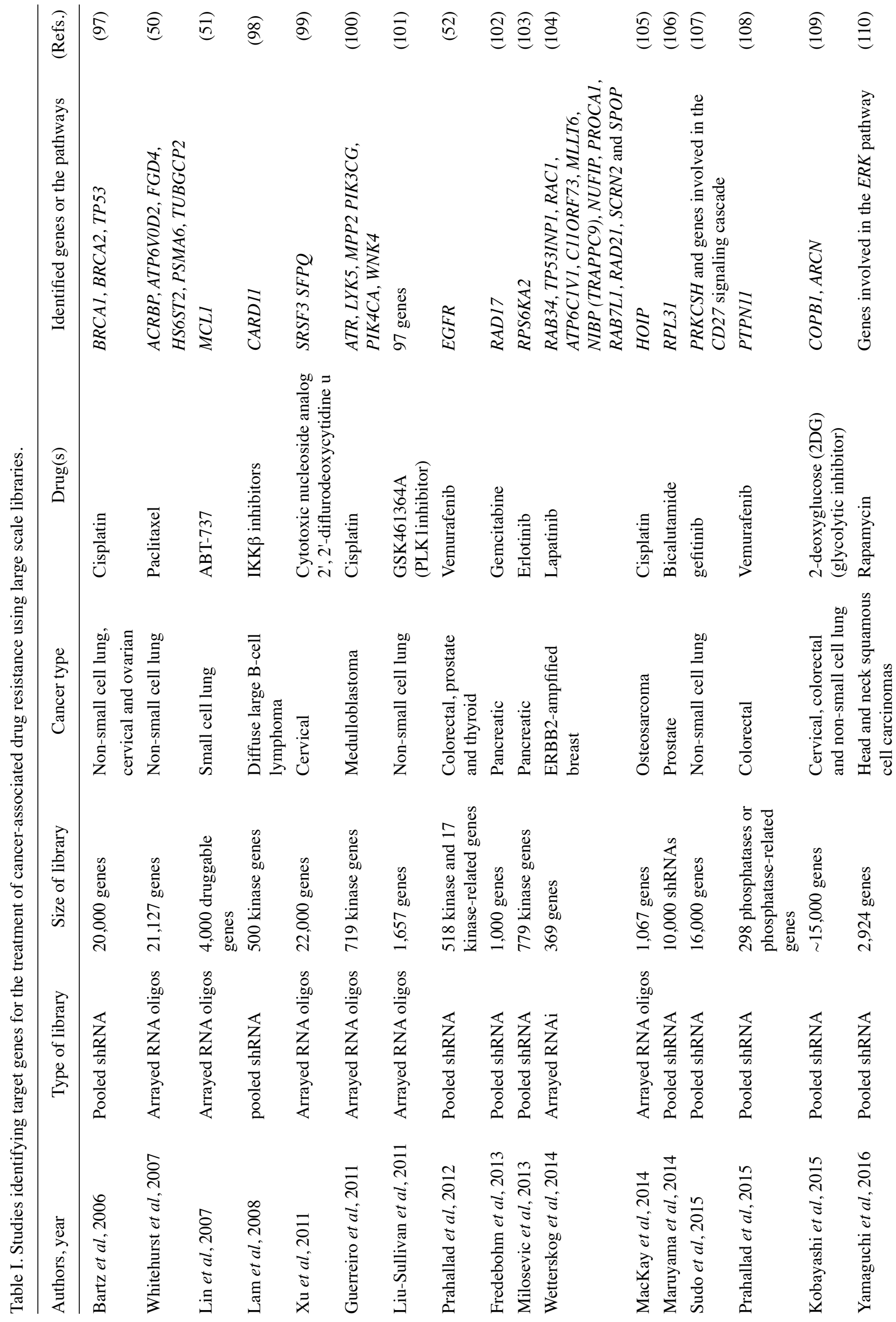


Immune therapy using immune checkpoint inhibitors provides significant clinical benefit to patients with various types of cancer, including melanoma, lymphoma, and lung cancer (57). However, intrinsic or acquired resistance inevitably occurs, limiting the clinical benefits (49). Using genome-wide CRISPR-Cas9 or siRNA libraries, two studies identified $A P L N R$ (encoding the apelin receptor) and C-C motif chemokine receptor 9 as genes that may cause resistance to immune checkpoint inhibitors $(58,59)$.

Invasion and migration. Metastasis is significantly associated with a poor patient prognosis, and patients with metastatic cancer exhibit poor survival outcomes (60). Metastasis comprises several sequential steps: i) Migration from a primary site; ii) intravasation; iii) passage by blood flow; iv) extravasation; v) and final settlement at distant sites. To complete this process, cancer cells must acquire the ability to invade and migrate and cancer cells exhibit these oncogenic properties. Previous studies demonstrated that epithelial-mesenchymal transition (EMT) significantly contributes to metastasis in cancer cells $(61,62)$. EMT, and its reverse phenomenon MET, were initially identified during embryonic development, in which embryonic cells transform into terminally differentiated, specialized cells via several cycles of EMT and MET (61). A number of studies suggest a central role of EMT in metastasis (63-65). Previous studies have identified target genes for inhibiting migration and/or invasion ability of cancer cells through library screening. Pavan et al (66) developed a system combining RNAi library screening with a microscopy-based high-throughput quantitative analysis to identify a signaling pathway contributing to EMT in breast cancer. The group identified 59 genes whose inhibition suppressed transforming growth factor $\beta$-induced EMT in immortalized epithelial normal murine mammary gland cells. In addition, Pavan et al (66) focused on MEK5 and ERK5 belonging to the same signaling pathway and demonstrated the potential of targeting MEK5 and ERK5 as an anti-metastatic mechanism. Another study used migration ability as a phenotype for functional screening, identifying genes contributing to migration in glioblastoma, a highly invasive cancer (67). The authors performed a genome-wide RNAi screening in glioblastoma cells with a functional selection of cells able to migrate through Matrigel, identifying two genes [KH-type splicing regulatory protein $(K H S R P)$ and host cell factor $\mathrm{Cl}(\mathrm{HCFCl})$ ] as targets of invasion-suppressing therapeutics for glioblastoma.

Resistance to anoikis: Anchorage-independent growth. Upon detachment from the extracellular matrix or neighboring cells, normal epithelial cells undergo a type of apoptosis called anoikis (68). Anoikis prevents normal epithelial cells from colonizing at different organ sites, thereby maintaining the integrity of the body (68). Most cancer cells acquire resistance to anoikis, which is called anchorage-independent growth (AIG). The ability of AIG allows cancer cells to metastasize to different organs and is considered a hallmark of cancer cells (64). Several different molecular mechanisms underlying AIG have been identified, including the induction of intrinsic and extrinsic anti-apoptotic signaling, often triggered by changes in the expression patterns of integrin family members $(68,69)$. In addition, previous studies have 
demonstrated the role of EMT in AIG $(68,70)$; however, the underlying molecular mechanisms of AIG are yet to be elucidated.

Eskiocak et al (71) used the immortalized untransformed colon epithelial cell line HCEC as a model system to evaluate the effects of shRNA-mediated knockdown of selected genes on AIG. The effects of the knockdown of 151 candidate cancer genes ( $C A N$-genes), which have been identified as genes most likely to be drivers in breast and colorectal cancers, via a comprehensive statistical and bioinformatic analysis (72), were evaluated and revealed that $C A N$-genes are enriched in AIG suppressors. In addition, Simpson et al conducted a genome-wide shRNA screening to identify anoikis-resistant genes by culturing immortalized prostate and nasopharyngeal untransformed cell lines in a suspension condition, which identified $\alpha / \beta$ hydrolase domain containing $4(A B H D 4)$ as a promising target for inducing anoikis (73).

Resistance to oncogene-induced senescence (OIS). Activation of certain types of oncogenes, such as mutant KRAS and $B R A F$, causes normal cells to undergo senescence $(74,75)$. This type of senescence is stress-induced and is termed OIS (74,75). OIS functions as a barrier to carcinogenesis initiated by normal cells, whereas senescence-associated secretory phenotype ( $S A S P$ ) is a carcinogenesis-promoting aspect of OIS (76). OIS was discovered by Serrano et al (77), who demonstrated that oncogenic ras induces premature senescence in experimental cell cultures. Subsequently, the occurrence of OIS in human disease was demonstrated in a developmental process of melanoma. Two studies revealed that OIS prevents benign melanocytic nevi, presumed to be the origin of melanoma, from transforming to overt melanoma $(78,79)$. These studies demonstrated that proliferation of nevi cells is suppressed at very low levels despite harboring the highly oncogenic mutation $B R A F V 600$. Studies have also revealed that $B R A F V 600$-induced OIS is associated with p16INK4A upregulation $(78,79)$; however, other unidentified changes may also be involved because of the complex mechanisms governing senescence (80). Therefore, several studies have attempted to the identify genes that may facilitate cells to bypass senescence induced by oncogenic $R A S$ or $B R A F$. Vicent et al (81) performed RNAi screening to identify genes that facilitate bypassing ras-induced OIS in mouse models, reporting that $\mathrm{Wt} 1$ transcription factor $(W t 1)$ is an OIS-bypassing gene using both in vitro and in vivo models. Vicent et al (81) also demonstrated WTl to be an independent prognostic factor in patients with $K R A S$-mutated lung cancer. Another study performed a near-genome-wide screening ( $\sim 15,000$ genes) to identify regulators of BRAFV600-induced senescence and identified RASSF as an OIS suppressor (82). Some screenings searching for OIS-bypassing genes used primary normal culture, and immortalized untransformed normal cell lines as model systems $(82,83)$ because these cells are more prone to exhibit OIS, primarily due to their intact senescent machinery. However, the ability of cancer cells to undergo OIS may be impaired because of alterations in genes involved in senescence (74). Therefore, the applicability of the identified OIS-bypassing genes needs to be validated in multiple human cancer cell lines before exploring their usefulness as drug targets.
Cancer stemness. The cancer stem cell (CSC) theory hypothesizes that CSCs have the ability to self-renew and to differentiate into phenotypically diverse cancer cells (84). Although the CSC concept has not been demonstrated, accumulating evidence suggests that a number of types of cancer harbor CSCs $(84,85)$. Notably, CSCs are hypothesized to be resistant to chemotherapy and irradiation (84). Therefore, the development of CSC-targeted therapeutics is attracting attention because of its potential to eradicate cancer cells. A functional library screening based on the sphere-forming ability of breast cancer cell lines identified ATG4 as a promotor of the breast CSC-like phenotype (86). However, the usefulness of a sphere-formation assay for evaluating the self-renewal capacity is based on the assumption that the assay developed for normal neural stem cells can be accurately used for CSCs. Therefore, validation of genes identified as cancer stemness genes by other assays, such as a transplantation assays and lineage-tracing approaches, are required.

Genomic Instability. A phenotype of genomic instability facilitates diverse oncogenic properties because it causes numerous mutations resulting from the activation of oncogenic genes or inactivation of tumor suppressive genes (87). A previous study performed a genome-wide RNAi screen to identified the pathways and specific genes mediating genomic stability (88). A screen using elevation of $\gamma \mathrm{H} 2 \mathrm{~A} . \mathrm{X}$ variant histone (H2AX; a marker of double strand DNA damage) as an indicator for detecting DNA damage was conducted in HeLa cancer cells, identifying genes involved in DNA replication, checkpoint activation and DNA repair. The identified genes included TIMELESS and TIPIN encoding proteins that form a complex, leading to activation of the replication checkpoint. The identified genes may serve as promising drug targets to restore genomic stability in cancer cells (88).

Tumor growth in vivo. Tumor growth in vivo represents a more accurate screening method because it accounts for several aspects of real tumor growth, including 3-D condition, requirements for angiogenesis and the microenvironment (89).

One critical issue of in vivo pooled library screening is the difficulty in ensuring appropriate representation of the entire library in the initial population inoculated into model animals (89). There is a limitation to the maximum number of cells that can be inoculated, which limits the size and complexity of the library. Notably, the minimum cell numbers required for each shRNA differ significantly, depending on whether tumor suppressor genes or oncogenic genes are targeted for screening (89). In the case of oncogenic gene-targeted screening, low library representation tends to result in false-positive results, so instead of using genome-wide libraries, researchers used libraries focused on specific types of genes in order to identify oncogenic genes. For example, Singh et al (90) used an shRNA library of 150 genes associated with brain metastasis to conduct a library screening consisting of both in vivo (intracranial injection) and in vitro (tumor sphere-forming assay) assays to identify metastasis-promoting genes. The group successfully identified SPARC (osteonectin), cwcv and kazal like domains proteoglycan 1 (SPOCK1) and twist family bHLH transcription factor 2 (TWIST2) as 
regulators of brain metastasis-initiating cells. In addition, most studies using in vivo genome-wide or near-genome-wide RNAi models discovered tumor-suppressive genes $(91,92)$.

\section{Conclusions and future perspectives}

Shortly after RNAi technology for gene knockdown was developed in the laboratory, attempts to conduct large-scale functional screenings with RNAi were initiated (93). In addition, a gene knockout technique, CRISPR-Cas9 was also introduced for laboratory use (94). For $>10$ years, researchers have extensively conducted functional genomic screening to identify better targets and to develop new therapeutics for cancer. The present paper reviewed and summarized knowledge obtained by these studies, which has the potential to be used for drug development. Nevertheless, breakthroughs that can be immediately translated into clinical use are yet to be made. In particular, despite many reported studies, $K R A S$ synthetic genes that have been reproducibly confirmed have not been successfully identified; therefore, development of KRAS-synthetic lethal drugs has not been successful. Project DRIVE suggested that no single synthetic lethal genes for $K R A S$ exist. However, there may be certain strategies potentially enabling the identification of true KRAS synthetic genes; for example, one approach may be using more realistic modeling systems to evaluate malignant phenotypes. Such models may include a 3-D culture of cell lines and patient-derived xenografts $(95,96)$, although such models are usually difficult to manage for large-scale screening. Due to the large heterogeneity in coexisting genomic alterations among $K R A S$-mutated tumors, studies using cancer cells may suffer from the presence of high background of noise during screening. Therefore, focus is needed on cancer cells which have higher similarities in harbored genetic alterations in addition to mutant KRAS.

An improvement in consistency of identified genes from a genome-wide screen has been revealed in CRISPR-Cas9 knockout compared with shRNA techniques (28). However, pharmacological inhibition of gene function with compounds is usually incomplete; thus, target genes identified through partial knockdown with RNAi represent improved targets. Therefore, results from CRISPR-Cas9 and RNAi screens need to be regarded as complementary.

In conclusion, advances in the technology of gene silencing and next generation sequencing have enabled researchers to conduct large-scale high-throughput phenotypic screenings, resulting in the identification of numerous potential novel drug targets for cancer. However, there are several issues, such as low reproducibility in the identified genes (40). Thus, substantial effort is required to adequately address these problems in order to identify novel cancer drug target genes.

\section{Acknowledgements}

Not applicable.

\section{Funding}

The present work was supported by grants from Grant-in-Aid for Scientific Research (grant no. 18H02819) and a Challenging
Research Exploratory grant from the Japan Society for the Promotion of Science (grant no. 19K22617).

\section{Availability of data and materials}

Data sharing is not applicable to this article, as no datasets were generated or analyzed during the current study.

\section{Author's contributions}

MS designed the review, researched the literature and wrote the manuscript.

\section{Ethics approval and consent to participate}

Not applicable.

\section{Patient consent for publication}

Not applicable.

\section{Competing interests}

The author declares that he has no competing interests.

\section{References}

1. Armitage $\mathrm{P}$ and Doll R: The age distribution of cancer and a multi-stage theory of carcinogenesis. Br J Cancer 8: 1-12, 1954.

2. Vogelstein B and Kinzler KW: The multistep nature of cancer. Trends Genet 9: 138-141, 1993.

3. Chaffer CL and Weinberg RA: How does multistep tumorigenesis really proceed? Cancer Discov 5: 22-24, 2015.

4. Barretina J, Caponigro G, Stransky N, Venkatesan K, Margolin AA, Kim S, Wilson CJ, Lehár J, Kryukov GV, Sonkin D, et al: The cancer cell line encyclopedia enables predictive modelling of anticancer drug sensitivity. Nature 483: 603-607, 2012.

5. Bailey MH, Tokheim C, Porta-Pardo E, Sengupta S, Bertrand D, Weerasinghe A, Colaprico A, Wendl MC, Kim J, Reardon B, et al: Comprehensive characterization of cancer driver genes and mutations. Cell 173: 371-385 e18, 2018.

6. Garraway LA and Lander ES: Lessons from the cancer genome. Cell 153: 17-37, 2013.

7. Seshadri R, Matthews C, Dobrovic A and Horsfall DJ: The significance of oncogene amplification in primary breast cancer. Int J Cancer 43: 270-272, 1989.

8. Davies H, Bignell GR, Cox C, Stephens P, Edkins S, Clegg S, Teague J, Woffendin H, Garnett MJ, Bottomley W, et al: Mutations of the BRAF gene in human cancer. Nature 417: 949-954, 2002.

9. Lynch TJ, Bell DW, Sordella R, Gurubhagavatula S, Okimoto RA, Brannigan BW, Harris PL, Haserlat SM, Supko JG, Haluska FG, et al: Activating mutations in the epidermal growth factor receptor underlying responsiveness of non-small-cell lung cancer to gefitinib. N Engl J Med 350: 2129-2139, 2004.

10. Paez JG, Jänne PA, Lee JC, Tracy S, Greulich H, Gabriel S, Herman P, Kaye FJ, Lindeman N, Boggon TJ, et al: EGFR mutations in lung cancer: Correlation with clinical response to gefitinib therapy. Science 304: 1497-1500, 2004.

11. Hirsch FR, Scagliotti GV, Mulshine JL, Kwon R, Curran WJ Jr, Wu YL and Paz-Ares L: Lung cancer: Current therapies and new targeted treatments. Lancet 389: 299-311, 2017.

12. Sato M, Shames DS, Gazdar AF and Minna JD: A translational view of the molecular pathogenesis of lung cancer. $J$ Thorac Oncol 2: 327-343, 2007.

13. Murugan AK, Grieco $M$ and Tsuchida N: RAS mutations in human cancers: Roles in precision medicine. Semin Cancer Biol 59: 23-35, 2019.

14. Ryan MB and Corcoran RB: Therapeutic strategies to target RAS-mutant cancers. Nat Rev Clin Oncol 15: 709-720, 2018. 
15. Govindan R, Fakih M, Price T, Falchook G, Desai J, Kuo J, Strickler J, Krauss J, Li B, Denlinger C, et al: OA02.02 Phase 1 study of safety, tolerability, PK and efficacy of AMG 510, a novel KRASG12C inhibitor, evaluated in NSCLC. J Thorac Oncol 14 (Suppl): S208, 2019.

16. Canon J,Rex K, Saiki AY, Mohr C, Cooke K, BagalD, Gaida K,Holt T, Knutson CG, Koppada N, et al: The clinical KRAS(G12C) inhibitor AMG 510 drives anti-tumour immunity. Nature 575: 217-223, 2019.

17. Vogelstein B, Papadopoulos N, Velculescu VE, Zhou S, Diaz LA $\mathrm{Jr}$ and Kinzler KW: Cancer genome landscapes. Science 339: 1546-1558, 2013.

18. Nagel R, Semenova EA and Berns A: Drugging the addict: Non-oncogene addiction as a target for cancer therapy. EMBO Rep 17: 1516-1531, 2016.

19. Dai C, Whitesell L, Rogers AB and Lindquist S: Heat shock factor 1 is a powerful multifaceted modifier of carcinogenesis. Cell 130: 1005-1018, 2007.

20. McDonald ER III, de Weck A, Schlabach MR, Billy E, Mavrakis KJ, Hoffman GR, Belur D, Castelletti D, Frias E, Gampa K, et al: Project DRIVE: A compendium of cancer dependencies and synthetic lethal relationships uncovered by large-scale, deep RNAi screening. Cell 170: 577-592 e10, 2017.

21. Schuster A, Erasimus H, Fritah S, Nazarov PV, van Dyck E, Niclou SP and Golebiewska A: RNAi/CRISPR Screens: From a pool to a valid hit. Trends Biotechnol 37: 38-55, 2019.

22. Schlabach MR, Luo J, Solimini NL, Hu G, Xu Q, Li MZ, Zhao Z, Smogorzewska A, Sowa ME, Ang XL, et al: Cancer proliferation gene discovery through functional genomics. Science 319: 620-624, 2008.

23. Silva JM, Marran K, Parker JS, Silva J, Golding M, Schlabach MR, Elledge SJ, Hannon GJ and Chang K: Profiling essential genes in human mammary cells by multiplex RNAi screening. Science 319: 617-620, 2008.

24. Cheung HW, Cowley GS, Weir BA, Boehm JS, Rusin S, Scott JA, East A, Ali LD, Lizotte PH, Wong TC, et al: Systematic investigation of genetic vulnerabilities across cancer cell lines reveals lineage-specific dependencies in ovarian cancer. Proc Natl Acad Sci USA 108: 12372-12377, 2011.

25. Cowley GS, Weir BA, Vazquez F, Tamayo P, Scott JA, Rusin S, East-Seletsky A, Ali LD, Gerath WF, Pantel SE, et al: Parallel genome-scale loss of function screens in 216 cancer cell lines for the identification of context-specific genetic dependencies. Sci Data 1: 140035, 2014

26. Marcotte R, Brown KR, Suarez F, Sayad A, Karamboulas K, Krzyzanowski PM, Sircoulomb F, Medrano M, Fedyshyn Y, Koh JLY, et al: Essential gene profiles in breast, pancreatic, and ovarian cancer cells. Cancer Discov 2: 172-189, 2012.

27. Ran FA, Hsu PD, Wright J, Agarwala V, Scott DA and Zhang F: Genome engineering using the CRISPR-Cas9 system. Nat Protoc 8: 2281-2308, 2013.

28. Shalem O, Sanjana NE, Hartenian E, Shi X, Scott DA, Mikkelson T, Heckl D, Ebert BL, Root DE, Doench JG and Zhang F: Genome-scale CRISPR-Cas9 knockout screening in human cells. Science 343: 84-87, 2014.

29. Wang T, Wei JJ, Sabatini DM and Lander ES: Genetic screens in human cells using the CRISPR-Cas9 system. Science 343: 80-84, 2014.

30. Kakumu T, Sato M, Goto D, Kato T, Yogo N, Hase T, Morise M, Fukui T, Yokoi K, Sekido Y, et al: Identification of proteasomal catalytic subunit PSMA6 as a therapeutic target for lung cancer. Cancer Sci 108: 732-743, 2017.

31. Tanaka I, Sato M, Kato T, Goto D, Kakumu T, Miyazawa A, Yogo N, Hase T, Morise M, Sekido Y, et al: eIF2 $\beta$, a subunit of translation-initiation factor EIF2, is a potential therapeutic target for non-small cell lung cancer. Cancer Sci 109: 1843-1852, 2018

32. O'Neil NJ, Bailey ML and Hieter P: Synthetic lethality and cancer. Nat Rev Genet 18: 613-623, 2017.

33. Hsu TY, Simon LM, Neill NJ, Marcotte R, Sayad A, Bland CS, Echeverria GV, Sun T, Kurley SJ, Tyagi S, et al: The spliceosome is a therapeutic vulnerability in MYC-driven cancer. Nature 525: 384-388, 2015

34. Kumar MS, Hancock DC, Molina-Arcas M, Steckel M, East P, Diefenbacher M, Armenteros-Monterroso E, Lassailly F, Matthews N, Nye E, et al: The GATA2 transcriptional network is requisite for RAS oncogene-driven non-small cell lung cancer. Cell 149: 642-655, 2012.

35. Luo J, Emanuele MJ, Li D, Creighton CJ, Schlabach MR, Westbrook TF, Wong KK and Elledge SJ: A genome-wide RNAi screen identifies multiple synthetic lethal interactions with the Ras oncogene. Cell 137: 835-848, 2009.
36. Scholl C, Fröhling S, Dunn IF, Schinzel AC, Barbie DA, Kim SY, Silver SJ, Tamayo P, Wadlow RC, Ramaswamy S, et al: Synthetic lethal interaction between oncogenic KRAS dependency and STK33 suppression in human cancer cells. Cell 137: 821-834, 2009.

37. Barbie DA, Tamayo P, Boehm JS, Kim SY, Moody SE, Dunn IF, Schinzel AC, Sandy P, Meylan E, Scholl C, et al: Systematic RNA interference reveals that oncogenic KRAS-driven cancers require TBK1. Nature 462: 108-112, 2009.

38. Wang Y, Ngo VN, Marani M, Yang Y, Wright G, Staudt LM and Downward J: Critical role for transcriptional repressor Snail2 in transformation by oncogenic RAS in colorectal carcinoma cells. Oncogene 29: 4658-4670, 2010.

39. Costa-Cabral S, Brough R, Konde A, Aarts M, Campbell J, Marinari E, Riffell J, Bardelli A, Torrance C, Lord CJ and Ashworth A: CDK1 is a synthetic lethal target for KRAS mutant tumours. PLoS One 11: e0149099, 2016.

40. Downward J: RAS synthetic lethal screens revisited: Still seeking the elusive prize? Clin Cancer Res 21: 1802-1809, 2015.

41. Babij C, Zhang Y, Kurzeja RJ, Munzli A, Shehabeldin A, Fernando M, Quon K, Kassner PD, Ruefli-Brasse AA, Watson VJ, et al: STK33 kinase activity is nonessential in KRAS-dependent cancer cells. Cancer Res 71: 5818-5826, 2011.

42. Fröhling S and Scholl C: STK33 kinase is not essential in KRAS-dependent cells-letter. Cancer Res 71: 7716; author reply $7717,2011$.

43. Forbes SA, Beare D, Boutselakis H, Bamford S, Bindal N, Tate J, Cole CG, Ward S, Dawson E, Ponting L, et al: COSMIC: Somatic cancer genetics at high-resolution. Nucleic Acids Res 45D: D777-D783, 2017.

44. Behan FM, Iorio F, Picco G, Gonçalves E, Beaver CM, Migliardi G, Santos R, Rao Y, Sassi F, Pinnelli M, et al: Prioritization of cancer therapeutic targets using CRISPR-Cas9 screens. Nature 568: 511-516, 2019.

45. Chan EM, Shibue T, McFarland JM, Gaeta B, Ghandi M, Dumont N, Gonzalez A, McPartlan JS, Li T, Zhang Y, et al: WRN helicase is a synthetic lethal target in microsatellite unstable cancers. Nature 568: 551-556, 2019.

46. Aggarwal M, Banerjee T, Sommers JA, Iannascoli C, Pichierri P, Shoemaker RH and Brosh RM Jr: Werner syndrome helicase has a critical role in DNA damage responses in the absence of a functional fanconi anemia pathway. Cancer Res 73: 5497-5507, 2013.

47. Holohan C, Van Schaeybroeck S, Longley DB and Johnston PG: Cancer drug resistance: An evolving paradigm. Nat Rev Cancer 13: 714-726, 2013

48. Gottesman MM, Lavi O, Hall MD and Gillet JP: Toward a better understanding of the complexity of cancer drug resistance. Annu Rev Pharmacol Toxicol 56: 85-102, 2016.

49. Jackson CM, Choi J and Lim M: Mechanisms of immunotherapy resistance: Lessons from glioblastoma. Nat Immunol 20: 1100-1109, 2019

50. Whitehurst AW, Bodemann BO, Cardenas J, Ferguson D, Girard L, Peyton M, Minna JD, Michnoff C, Hao W, Roth MG, et al: Synthetic lethal screen identification of chemosensitizer loci in cancer cells. Nature 446: 815-819, 2007.

51. Lin X, Morgan-Lappe S, Huang X, Li L, Zakula DM, Vernetti LA, Fesik SW and Shen Y: 'Seed' analysis of off-target siRNAs reveals an essential role of Mcl-1 in resistance to the small-molecule Bcl-2/Bcl-XL inhibitor ABT-737. Oncogene 26: 3972-3979, 2007.

52. Prahallad A, Sun C, Huang S, Di Nicolantonio F, Salazar R, Zecchin D, Beijersbergen RL, Bardelli A and Bernards R: Unresponsiveness of colon cancer to BRAF(V600E) inhibition through feedback activation of EGFR. Nature 483: 100-103, 2012.

53. Kurata M, Rathe SK, Bailey NJ, Aumann NK, Jones JM, Veldhuijzen GW, Moriarity BS and Largaespada DA: Using genome-wide CRISPR library screening with library resistant DCK to find new sources of Ara-C drug resistance in AML. Sci Rep 6: 36199, 2016.

54. Hou P, Wu C, Wang Y, Qi R, Bhavanasi D, Zuo Z, Dos Santos C, Chen S, Chen Y, Zheng H, et al: A Genome-wide CRISPR screen identifies genes critical for resistance to FLT3 inhibitor AC220. Cancer Res 77: 4402-4413, 2017.

55. Sun W, He B, Yang B, Hu W, Cheng S, Xiao H, Yang Z, Wen X, Zhou L, Xie H, et al: Genome-wide CRISPR screen reveals SGOL1 as a druggable target of sorafenib-treated hepatocellular carcinoma. Lab Invest 98: 734-744, 2018.

56. Sustic T, van Wageningen S, Bosdriesz E, Reid RJD, Dittmar J, Lieftink C, Beijersbergen RL, Wessels LFA, Rothstein R and Bernards R: A role for the unfolded protein response stress sensor ERN1 in regulating the response to MEK inhibitors in KRAS mutant colon cancers. Genome Med 10: 90, 2018. 
57. Sharma P and Allison JP: The future of immune checkpoint therapy. Science 348: 56-61, 2015.

58. Khandelwal N, Breinig M, Speck T, Michels T, Kreutzer C, Sorrentino A, Sharma AK, Umansky L, Conrad H, Poschke I, et al: A high-throughput RNAi screen for detection of immune-checkpoint molecules that mediate tumor resistance to cytotoxic T lymphocytes. EMBO Mol Med 7: 450-463, 2015.

59. Patel SJ, Sanjana NE, Kishton RJ, Eidizadeh A, Vodnala SK, Cam M, Gartner JJ, Jia L, Steinberg SM, Yamamoto TN, et al: Identification of essential genes for cancer immunotherapy. Nature 548: 537-542, 2017.

60. Steeg PS: Targeting metastasis. Nat Rev Cancer 16: 201-218, 2016.

61. Thiery JP, Acloque H, Huang RY and Nieto MA: Epithelial-mesenchymal transitions in development and disease. Cell 139: 871-890, 2009.

62. Sato M, Shames DS and Hasegawa Y: Emerging evidence of epithelial-to-mesenchymal transition in lung carcinogenesis. Respirology 17: 1048-1059, 2012.

63. Chaffer CL, San Juan BP, Lim E and Weinberg RA: EMT, cell plasticity and metastasis. Cancer Metastasis Rev 35: 645-654, 2016.

64. Yilmaz M and Christofori G: EMT, the cytoskeleton, and cancer cell invasion. Cancer Metastasis Rev 28: 15-33, 2009.

65. Heerboth S, Housman G, Leary M, Longacre M, Byler S, Lapinska K, Willbanks A and Sarkar S: EMT and tumor metastasis. Clin Transl Med 4: 6, 2015.

66. Pavan S, Meyer-Schaller N, Diepenbruck M, Kalathur RKR, Saxena M and Christofori G: A kinome-wide high-content siRNA screen identifies MEK5-ERK5 signaling as critical for breast cancer cell EMT and metastasis. Oncogene 37: 4197-4213, 2018.

67. Yang J, Fan J, Li Y, Li F, Chen P, Fan Y, Xia X and Wong ST: Genome-wide RNAi screening identifies genes inhibiting the migration of glioblastoma cells. PLoS One 8: e61915, 2013.

68. Paoli P, Giannoni E and Chiarugi P: Anoikis molecular pathways and its role in cancer progression. Biochim Biophys Acta 1833 3481-3498, 2013.

69. Taddei ML, Giannoni E, Fiaschi T and Chiarugi P: Anoikis: An emerging hallmark in health and diseases. J Pathol 226: 380-393, 2012.

70. Takeyama Y, Sato M, Horio M, Hase T, Yoshida K, Yokoyama T, Nakashima H, Hashimoto N, Sekido Y, Gazdar AF, et al: Knockdown of ZEB1, a master epithelial-to-mesenchymal transition (EMT) gene, suppresses anchorage-independent cell growth of lung cancer cells. Cancer Lett 296: 216-224, 2010.

71. Eskiocak U, Kim SB, Ly P, Roig AI, Biglione S, Komurov K Cornelius C, Wright WE, White MA and Shay JW: Functional parsing of driver mutations in the colorectal cancer genome reveals numerous suppressors of anchorage-independent growth. Cancer Res 71: 4359-4365, 2011.

72. Wood LD, Parsons DW, Jones S, Lin J, Sjöblom T, Leary RJ, Shen D, Boca SM, Barber T, Ptak J, et al: The genomic landscapes of human breast and colorectal cancers. Science 318: 1108-1113, 2007

73. Simpson CD, Hurren R, Kasimer D, MacLean N, Eberhard Y, Ketela T, Moffat J and Schimmer AD: A genome wide shRNA screen identifies $\alpha / \beta$ hydrolase domain containing 4 (ABHD4) as a novel regulator of anoikis resistance. Apoptosis 17: 666-678, 2012.

74. Larsson LG: Oncogene- and tumor suppressor gene-mediated suppression of cellular senescence. Semin Cancer Biol 21: 367-376, 2011.

75. Gorgoulis VG and Halazonetis TD: Oncogene-induced senescence: The bright and dark side of the response. Curr Opin Cell Biol 22: 816-827, 2010.

76. Faget DV, Ren Q and Stewart SA: Unmasking senescence: Context-dependent effects of SASP in cancer. Nat Rev Cancer 19: 439-453, 2019

77. Serrano M, Lin AW, McCurrach ME, Beach D and Lowe SW: Oncogenic ras provokes premature cell senescence associated with accumulation of p53 and p16INK4a. Cell 88: 593-602, 1997.

78. Michaloglou C, Vredeveld LC, Soengas MS, Denoyelle C, Kuilman T, van der Horst CM, Majoor DM, Shay JW, Mooi WJ and Peeper DS: BRAFE600-associated senescence-like cell cycle arrest of human naevi. Nature 436: 720-724, 2005.

79. Gray-Schopfer VC, Cheong SC, Chong H, Chow J, Moss T, Abdel-Malek ZA, Marais R, Wynford-Thomas D and Bennett DC: Cellular senescence in naevi and immortalisation in melanoma: A role for p16? Br J Cancer 95: 496-505, 2006.
80. He S and Sharpless NE: Senescence in health and disease. Cell 169: 1000-1011, 2017.

81. Vicent S, Chen R, Sayles LC, Lin C, Walker RG, Gillespie AK, Subramanian A, Hinkle G, Yang X, Saif S, et al: Wilms tumor 1 (WT1) regulates KRAS-driven oncogenesis and senescence in mouse and human models. J Clin Invest 120: 3940-3952, 2010.

82. Kaplon J, Hömig-Hölzel C, Gao L, Meissl K, Verdegaal EM, van der Burg SH, van Doorn R and Peeper DS: Near-genomewide RNAi screening for regulators of $\mathrm{BRAF}(\mathrm{V} 600 \mathrm{E})$-induced senescence identifies RASEF, a gene epigenetically silenced in melanoma. Pigment Cell Melanoma Res 27: 640-652, 2014.

83. Tordella L, Khan S, Hohmeyer A, Banito A, Klotz S, Raguz S, Martin N, Dhamarlingam G, Carroll T, González Meljem JM, et al: SWI/SNF regulates a transcriptional program that induces senescence to prevent liver cancer. Genes Dev 30: 2187-2198, 2016.

84. Batlle E and Clevers H: Cancer stem cells revisited. Nat Med 23 1124-1134, 2017.

85. Nassar D and Blanpain C: Cancer stem cells: Basic concepts and therapeutic implications. Annu Rev Pathol 11: 47-76, 2016.

86. WolfJ,DewiDL,Fredebohm J,Müller-DeckerK,FlechtenmacherC Hoheisel JD and Boettcher M: A mammosphere formation RNAi screen reveals that ATG4A promotes a breast cancer stem-like phenotype. Breast Cancer Res 15: R109, 2013.

87. Hanahan D and Weinberg RA: Hallmarks of cancer: The next generation. Cell 144: 646-674, 2011

88. Paulsen RD, Soni DV, Wollman R, Hahn AT, Yee MC, Guan A, Hesley JA, Miller SC, Cromwell EF, Solow-Cordero DE, et al: A genome-wide siRNA screen reveals diverse cellular processes and pathways that mediate genome stability. Mol Cell 35: 228-239, 2009

89. Gargiulo G, Serresi M, Cesaroni M, Hulsman D and van Lohuizen M: In vivo shRNA screens in solid tumors. Nat Protoc 9: 2880-2902, 2014

90. Singh M, Venugopal C, Tokar T, Brown KR, McFarlane N, Bakhshinyan D, Vijayakumar T, Manoranjan B, Mahendram S, Vora $\mathrm{P}$, et al: RNAi screen identifies essential regulators of human brain metastasis-initiating cells. Acta Neuropathol 134: 923-940, 2017

91. Lin L, Chamberlain L, Pak ML, Nagarajan A, Gupta R, Zhu LJ Wright CM, Fong KM, Wajapeyee N, Green MR: A large-scale RNAi-based mouse tumorigenesis screen identifies new lung cancer tumor suppressors that repress FGFR signaling. Cancer Discov 4: 1168-1181, 2014

92. Iorns E, Ward TM, Dean S, Jegg A, Thomas D, Murugaesu N, Sims D, Mitsopoulos C, Fenwick K, Kozarewa I, et al: Whole genome in vivo RNAi screening identifies the leukemia inhibitory factor receptor as a novel breast tumor suppressor. Breast Cancer Res Treat 135: 79-91, 2012.

93. Elbashir SM, Harborth J, Lendeckel W, Yalcin A, Weber K and Tuschl T: Duplexes of 21-nucleotide RNAs mediate RNA interference in cultured mammalian cells. Nature 411: 494-498, 2001.

94. Wang H, La Russa M and Qi LS: CRISPR/Cas9 in genome editing and beyond. Annu Rev Biochem 85: 227-264, 2016.

95. Nyga A, Cheema U and Loizidou M: 3D tumour models: Novel in vitro approaches to cancer studies. J Cell Commun Signal 5 239-248, 2011

96. Hidalgo M, Amant F, Biankin AV, Budinská E, Byrne AT, Caldas C, Clarke RB, de Jong S, Jonkers J, Mælandsmo GM, et al: Patient-derived xenograft models: An emerging platform for translational cancer research. Cancer Discov 4: 998-1013, 2014

97. Bartz SR, Zhang Z, Burchard J, Imakura M, Martin M, Palmieri A, Needham R, Guo J, Gordon M, Chung N, et al: Small interfering RNA screens reveal enhanced cisplatin cytotoxicity in tumor cells having both BRCA network and TP53 disruptions. Mol Cell Biol 26: 9377-9386, 2006.

98. Lam LT, Davis RE, Ngo VN, Lenz G, Wright G, Xu W, Zhao H, Yu X, Dang L and Staudt LM: Compensatory IKKalpha activation of classical NF-kappaB signaling during IKKbeta inhibition identified by an RNA interference sensitization screen. Proc Natl Acad Sci USA 105: 20798-20803, 2008.

99. Xu Y, Karlsson A and Johansson M: Identification of genes associated to $2^{\prime}, 2^{\prime}$-difluorodeoxycytidine resistance in HeLa cells with a lentiviral short-hairpin RNA library. Biochem Pharmacol 82: 210-215, 2011.

100. Guerreiro AS, Fattet S, Kulesza DW, Atamer A, Elsing AN, Shalaby T, Jackson SP, Schoenwaelder SM, Grotzer MA, Delattre O and Arcaro A: A sensitized RNA interference screen identifies a novel role for the PI3K p110 $\gamma$ isoform in medulloblastoma cell proliferation and chemoresistance. Mol Cancer Res 9: 925-935, 2011 
101. Liu-Sullivan N, Zhang J, Bakleh A, Marchica J, Li J, Siolas D, Laquerre S, Degenhardt YY, Wooster R, Chang K, et al: Pooled shRNA screen for sensitizers to inhibition of the mitotic regulator polo-like kinase (PLK1). Oncotarget 2: 1254-1264, 2011.

102. Fredebohm J, Wolf J, Hoheisel JD and Boettcher M: Depletion of RAD17 sensitizes pancreatic cancer cells to gemcitabine. J Cell Sci 126: 3380-3389, 2013

103. Milosevic N, Kühnemuth B, Mühlberg L, Ripka S, Griesmann H, Lölkes C, Buchholz M, Aust D, Pilarsky C, Krug S, et al: Synthetic lethality screen identifies RPS6KA2 as modifier of epidermal growth factor receptor activity in pancreatic cancer. Neoplasia 15: 1354-1362, 2013.

104. Wetterskog D, Shiu KK, Chong I, Meijer T, Mackay A, Lambros M, Cunningham D, Reis-Filho JS, Lord CJ and Ashworth A: Identification of novel determinants of resistance to lapatinib in ERBB2-amplified cancers. Oncogene 33: 966-976, 2014.

105. MacKay C, Carroll E, Ibrahim AFM, Garg A, Inman GJ, Hay RT and Alpi AF: E3 ubiquitin ligase HOIP attenuates apoptotic cell death induced by cisplatin. Cancer Res 74: 2246-2257, 2014

106. Maruyama Y, Miyazaki T, Ikeda K, Okumura T, Sato W, Horie-Inoue K, Okamoto K, Takeda S and Inoue S: Short hairpin RNA library-based functional screening identified ribosomal protein L31 that modulates prostate cancer cell growth via p53 pathway. PLoS One 9: e108743, 2014.

107. Sudo M, Mori S, Madan V, Yang H, Leong G and Koeffler HP: Short-hairpin RNA library: Identification of therapeutic partners for gefitinib-resistant non-small cell lung cancer. Oncotarget 6 : 814-824, 2015.

108. Prahallad A, Heynen GJ, Germano G, Willems SM, Evers B, Vecchione L, Gambino V, Lieftink C, Beijersbergen RL, D Nicolantonio F, et al: PTPN11 is a central node in intrinsic and acquired resistance to targeted cancer drugs. Cell Rep 12: 1978-1985, 2015.
109. Kobayashi H, Nishimura H, Matsumoto K and Yoshida M: Identification of the determinants of 2-deoxyglucose sensitivity in cancer cells by shRNA library screening. Biochem Biophys Res Commun 467: 121-127, 2015.

110. Yamaguchi K, Iglesias-Bartolomé R, Wang Z, Callejas-Valera JL, Amornphimoltham P, Molinolo AA, Cohen EE, Califano JA, Lippman SM, Luo J and Gutkind JS: A synthetic-lethality RNAi screen reveals an ERK-mTOR co-targeting pro-apoptotic switch in PIK3CA+ oral cancers. Oncotarget 7: 10696-10709, 2016.

111. Yamanoi K, Matsumura N, Murphy SK, Baba T, Abiko K Hamanishi J, Yamaguchi K, Koshiyama M, Konishi I and Mandai M: Suppression of ABHD2, identified through a functional genomics screen, causes anoikis resistance, chemoresistance and poor prognosis in ovarian cancer. Oncotarget 7 : 47620-47636, 2016.

112. Combes E, Andrade AF, Tosi D, Michaud HA, Coquel F, Garambois V, Desigaud D, Jarlier M, Coquelle A, Pasero P, et al: Inhibition of ataxia-telangiectasia mutated and RAD3-related (ATR) overcomes oxaliplatin resistance and promotes antitumor immunity in colorectal cancer. Cancer Res 79: 2933-2946, 2019.

This work is licensed under a Creative Commons Attribution-NonCommercial-NoDerivatives 4.0 International (CC BY-NC-ND 4.0) License. 